\title{
Endogenous thyroid hormones modulate pituitary somatotroph differentiation during chicken embryonic development
}

\author{
L Liu' ${ }^{1}$ and T E Porter ${ }^{1,2}$ \\ ${ }^{1}$ Department of Animal and Avian Sciences, University of Maryland, College Park, Maryland 20742, USA \\ ${ }^{2}$ Molecular and Cell Biology Program, University of Maryland, College Park, Maryland 20742, USA \\ (Requests for offprints should be addressed to Email: TP44@UMAIL.UMD.EDU)
}

\begin{abstract}
Growth hormone cell differentiation normally occurs between day 14 and day 16 of chicken embryonic development. We reported previously that corticosterone (CORT) could induce somatotroph differentiation in vitro and in vivo and that thyroid hormones could act in combination with CORT to further augment the abundance of somatotrophs in vitro. The objective of the present study was to test our hypothesis that endogenous thyroid hormones regulate the abundance of somatotrophs during chicken embryonic development. Plasma samples were collected on embryonic day (e) 9-14. We found that plasma CORT and thyroid hormone levels increased progressively in mid-embryogenesis to e13 or e14, immediately before normal somatotroph differentiation. Administration of thyroxine $\left(\mathrm{T}_{4}\right)$ and triiodothyronine
\end{abstract}

$\left(T_{3}\right)$ into the albumen of fertile eggs on e11 increased somatotroph proportions prematurely on e13 in the developing chick embryos in vivo. Furthermore, administration of methimazole, the thyroid hormone synthesis inhibitor, on e9 inhibited somatotroph differentiation in vivo, as assessed on e14; this suppression was completely reversed by $T_{3}$ replacement on e11. Since we reported that $\mathrm{T}_{3}$ alone was ineffective in vitro, we interpret these findings to indicate that the effects of treatments in vivo were due to interactions with endogenous glucocorticoids. These results indicate that treatment with exogenous thyroid hormones can modulate somatotroph abundance and that endogenous thyroid hormone synthesis likely contributes to normal somatotroph differentiation.

Journal of Endocrinology (2004) 180, 45-53

\section{Introduction}

The anterior pituitary gland differentiates from Rathke's pouch into five distinct hormone-secreting cell types. The first functionally mature cell type to appear is the corticotroph. Differentiation of the other cell types is not autonomous and is controlled by various hormones and hypothalamic peptides (Dubois \& Hemming 1991, Dubois et al. 1997). We are studying the mechanisms regulating differentiation of growth hormone $(\mathrm{GH})$-secreting cells in the chicken anterior pituitary. Somatotrophs first become a significant population between embryonic day (e) 14 and e16 of chicken development (Porter et al. 1995a). Somatotroph differentiation does not occur in vitro without an extrapituitary signal, and glucocorticoids have been shown to induce somatotroph differentiation in chicken embryos and fetal rats in vitro and in vivo (Hemming et al. 1988, Nogami \& Tachibana 1993, Nogami et al. 1995, 1997, Morpurgo et al. 1997, Dean et al. 1999, Bossis \& Porter 2000, Porter et al. 2001, Liu et al. 2003).

Thyroid hormones play an important role in embryonic and neonatal development in mammals and birds. Studies with cultured fetal rat pituitary glands indicated that thyroid hormones exert their stimulatory action on fetal
GH gene expression and GH cell abundance only in the presence of glucocorticoids (Hemming et al. 1988, Nogami et al. 1997). Furthermore, Nogami et al. (1997) found that intraperitoneal injection of thyroxine $\left(\mathrm{T}_{4}\right)$ into pregnant rats, in the absence of concomitant dexamethasone treatment, failed to induce either GH cells or the accumulation of $\mathrm{GH}$ in the fetal pituitary gland. In contrast, adding methimazole (MMI) to the drinking water of pregnant rats suppressed $\mathrm{GH}$ cell number, $\mathrm{GH}$ content and GH mRNA level in the fetal pituitaries, and this suppression was reversed by additional intraperitoneal $\mathrm{T}_{4}$ injections to the pregnant dams (Nogami et al. 1995). However, as treatments were administered to the dams rather than directly to the fetuses in these studies, the effect of fetal-maternal interactions or maternal thyroid hormones could not be ruled out. Furthermore, as GH immunostaining in histology sections of the pituitary glands was evaluated in this study, quantitative determination of the total abundance of fetal somatotrophs was not achieved.

We found that thyroid hormones could act in combination with corticosterone (CORT) to further augment the abundance of somatotrophs in cultures of dispersed, chick embryonic pituitary cells, while having little or no 
effect on their own (Liu et al. 2003). However, the role played by thyroid hormones in modulating somatotroph differentiation in vivo during chicken or rat fetal development is not well understood.

In the present study, we measured plasma CORT and thyroid hormone levels during mid-embryogenesis to determine whether they increased prior to the substantial appearance of somatotrophs between e14 and e16. We then evaluated whether administration of thyroid hormones could increase somatotroph abundance in vivo. Finally, we examined whether inhibition of endogenous thyroid hormone synthesis could affect normal somatotroph differentiation.

\section{Materials and Methods}

Animals, egg injections and pituitary dispersions

All chicken embryos used in the present study were purchased from Allen's Hatchery (Seaford, DE, USA). All procedures with chicken embryos were approved by the Animal Care and Use Committee of the Univerisity of Maryland. Unless stated otherwise, all cell culture reagents were obtained from Gibco, and hormones and other chemicals were purchased from Sigma. Thyroid hormone stock solutions were prepared in $0.01 \mathrm{M} \mathrm{NaOH}$, and then diluted with water. All media were supplemented with $0 \cdot 1 \%$ BSA, $100 \mathrm{U} / \mathrm{ml}$ penicillin $\mathrm{G}$ and $100 \mu \mathrm{g} / \mathrm{ml}$ streptomycin sulfate. Fertile eggs were placed in a humidified incubator (GQF Manufacturing, Savannah, GA, USA) at $37.5{ }^{\circ} \mathrm{C}$. The typical length of incubation for chickens is 21 days. On e9 or e11, $100 \mu$ of the treatment solutions were injected $8 \mathrm{~mm}$ into the egg albumen through a hole punched in the small apical end of the egg. Embryos were removed on e13 or e14, and their anterior pituitary glands were isolated with the aid of a dissecting microscope. The pituitaries were then dissociated by a combination of trypsin digestion and mechanical agitation as described previously (Porter et al. 1995a,b, Morpurgo et al. 1997, Dean et al. 1999). The viability of the cells was assessed by the trypan blue dye exclusion method and was consistently greater than $95 \%$. The dispersed cells were assayed for detection of $\mathrm{GH}$-secreting or $\mathrm{GH}$-containing cells by reverse hemolytic plaque assay (RHPA) or immunocytochemistry (ICC) respectively.

Plasma sample collection and RIAs for CORT, triiodothyronine $\left(T_{3}\right)$ and $T_{4}$

Blood was collected from the chorioallantoic vessels of e9-e14 embryos. Blood was allowed to flow into capillary tubes coated with heparin and then centrifuged at $14000 \mathrm{~g}$ for $10 \mathrm{~min}$ to isolate the plasma. Plasma was stored at $-20{ }^{\circ} \mathrm{C}$ until subjected to double antibody RIA for CORT, $\mathrm{T}_{3}$ and $\mathrm{T}_{4}$. The tracers, $\left[{ }^{125} \mathrm{I}\right] \mathrm{CORT},\left[{ }^{125} \mathrm{I}\right] \mathrm{T}_{3}$ and $\left[{ }^{125} \mathrm{I}_{\mathrm{T}} \mathrm{T}_{4}\right.$, were purchased from Diagnostic Products Corporation (Los Angeles, CA, USA). Primary antibody for CORT was purchased from Fitzgerald Industries International, Inc (Concord, MA, USA). Primary antibodies for $T_{3}$ and $T_{4}$ were purchased from Endocrine Sciences (Calabasas Hills, CA, USA). Rabbit immunoglobulin ( $\operatorname{IgG})$ and secondary antibody (sheep anti-rabbit $\mathrm{IgG})$ were purchased from Sigma. Plasma was extracted with ether and stored at $-20^{\circ} \mathrm{C}$ until subjected to double antibody RIA for CORT; $40 \mu \mathrm{l}$ plasma were incubated with anti-CORT antibody (1:800 in PBS containing 0.8\% normal rabbit serum) and tracer at room temperature for $3 \mathrm{~h}$. After incubation with the second antibody at $4{ }^{\circ} \mathrm{C}$ overnight, $1 \mathrm{ml}$ cold PBS was added, the tubes were centrifuged and the supernatants were removed. The CORT radioactivity precipitated was measured by gamma counter. The $\mathrm{T}_{3}$ and $\mathrm{T}_{4}$ RIA were performed as described previously (McNabb \& Hughes 1983). Plasma from e9 embryos was pooled at two embryos per sample. All other ages were evaluated as individual embryos. Plasma (12.5 $\mu \mathrm{l}$ for $\mathrm{T}_{4}, 25 \mu \mathrm{l}$ for $\mathrm{T}_{3}$ ) was incubated with primary antisera, carrier IgG, barbital buffer (Sigma) and tracer at $37^{\circ} \mathrm{C}$ for $2 \mathrm{~h}$. After incubation with the second antibody at $4{ }^{\circ} \mathrm{C}$ overnight, $10 \%$ polyethylene glycol-8000 was added, the tubes were centrifuged, and the supernatants were removed. Assay sensitivity was $2.5 \mathrm{ng} / \mathrm{ml}$ for CORT, $0.125 \mathrm{ng} / \mathrm{ml}$ for $\mathrm{T}_{3}$ and $0.625 \mathrm{ng} / \mathrm{ml}$ for $\mathrm{T}_{4}$. Intra-assay coefficients of variation were determined by assaying a pooled sample 3, 6 and 6 times in the CORT, $T_{3}$ and $T_{4}$ assays respectively. Intra-assay coefficients of variation were $14.3,4.5$ and $17.6 \%$ for CORT, $\mathrm{T}_{3}$ and $\mathrm{T}_{4}$ respectively.

\section{Reverse hemolytic plaque assays (RHPA)}

The assays were performed according to the protocol described in detail previously (Porter et al. 1995a). Briefly, the harvested pituitary cells $\left(1 \cdot 0 \times 10^{5}\right.$ cells $\left./ \mathrm{ml}\right)$ were mixed with an equal volume of an $18 \%$ suspension of protein A-coated ovine erythrocytes and infused by capillary action into poly-L-lysine-coated Cunningham chambers. After cells were allowed to attach for $45 \mathrm{~min}$ $\left(37.5{ }^{\circ} \mathrm{C}\right.$; $95 \%$ air-5\% $\left.\mathrm{CO}_{2}\right)$, chambers were rinsed with Dulbecco's modified Eagle's medium (DMEM) to remove unattached cells. DMEM containing GH antiserum (1:40) and human GH-releasing hormone (hGHRH, $10^{-7} \mathrm{M}$ ) was then added to the resulting monolayer of cells, and replicate chambers were incubated for $20 \mathrm{~h}$ (three chambers per treatment). The GH antiserum used was as described and validated previously (Porter et al. 1995a). Plaque formation was subsequently induced by a $45 \mathrm{~min}$ incubation with guinea pig complement $(1: 40$, in DMEM). The cells were then fixed with $2 \%$ glutaraldehyde in $0.9 \%$ saline and stained with methyl green. Chambers were analyzed using a light microscope. $\mathrm{GH}$-positive cells were defined as those surrounded by a 
zone of hemolysis at least one lysed ovine erythrocyte in radius. Data shown are the percentage of all pituitary cells that formed plaques (i.e. secreted GH), with at least 200 pituitary cells counted per assay chamber.

\section{Immunocytochemistry (ICC)}

The harvested pituitary cells were diluted in DMEM to a concentration of $1.0 \times 10^{4}$ cells $/ \mathrm{ml}$ and were then attached to poly-L-lysine-coated 24-well tissue culture plates during a $1 \mathrm{~h}$ incubation period $\left(37.5^{\circ} \mathrm{C}\right.$; $95 \%$ air-5\% $\left.\mathrm{CO}_{2}\right)$. The plated cells were fixed with $3.7 \%$ formaldehyde in PBS for $20 \mathrm{~min}$. Cells were permeabilized with $0 \cdot 1 \%$ Tween-20/0 $1 \%$ Triton-X100 (8 min), quenched with $0 \cdot 3 \% \mathrm{H}_{2} \mathrm{O}_{2}(5 \mathrm{~min})$, blocked with $1 \%$ normal goat serum $(15 \mathrm{~min})$ and incubated overnight with rabbit anti-chicken GH (1:4000 in PBS) using the antiserum described above for the RHPA. The cells were rinsed with $\mathrm{PBS}$, and incubated with biotinylated goat anti-rabbit IgG for $30 \mathrm{~min}$. The cells were further processed using rabbit $\mathrm{ABC}$ kits according to the manufacturer's instructions (Vector Laboratories, Burlingame, CA, USA). VIP reagent (Vector) was used as substrate for the peroxidase. GH-containing cells were visually identified as exhibiting obvious staining using an inverted light microscope, and data shown are the percentage of the total pituitary cell population that contained GH.

\section{Statistical analysis}

Except for RIA results, the data reported are the means \pm S.E.M. from at least three completely separate experiments, with the number of replicate experiments provided in the legend to each Figure. Percentile data were transformed by taking the log of the arcsine of the ratio of GH cells to all pituitary cells. Transformed data were analyzed by ANOVA using the MIXED models procedure of SAS (SAS Institute, Cary, NC, USA). Differences between treatments were tested using Tukey's Studentized range test and were considered significant at $P<0 \cdot 05$.

\section{Results}

Plasma CORT and thyroid hormone levels increase by e14

We demonstrated previously that significant somatotroph differentiation occurs between day 14 and day 16 of chicken embryonic development and that CORT could induce somatotroph differentiation in vitro and in vivo. We also found that thyroid hormones could act in combination with CORT to further augment the abundance of somatotrophs by 3 days in cultures of chick embryo pituitary cells, while having little or no effect on their own (Liu et al. 2003). To determine whether CORT and
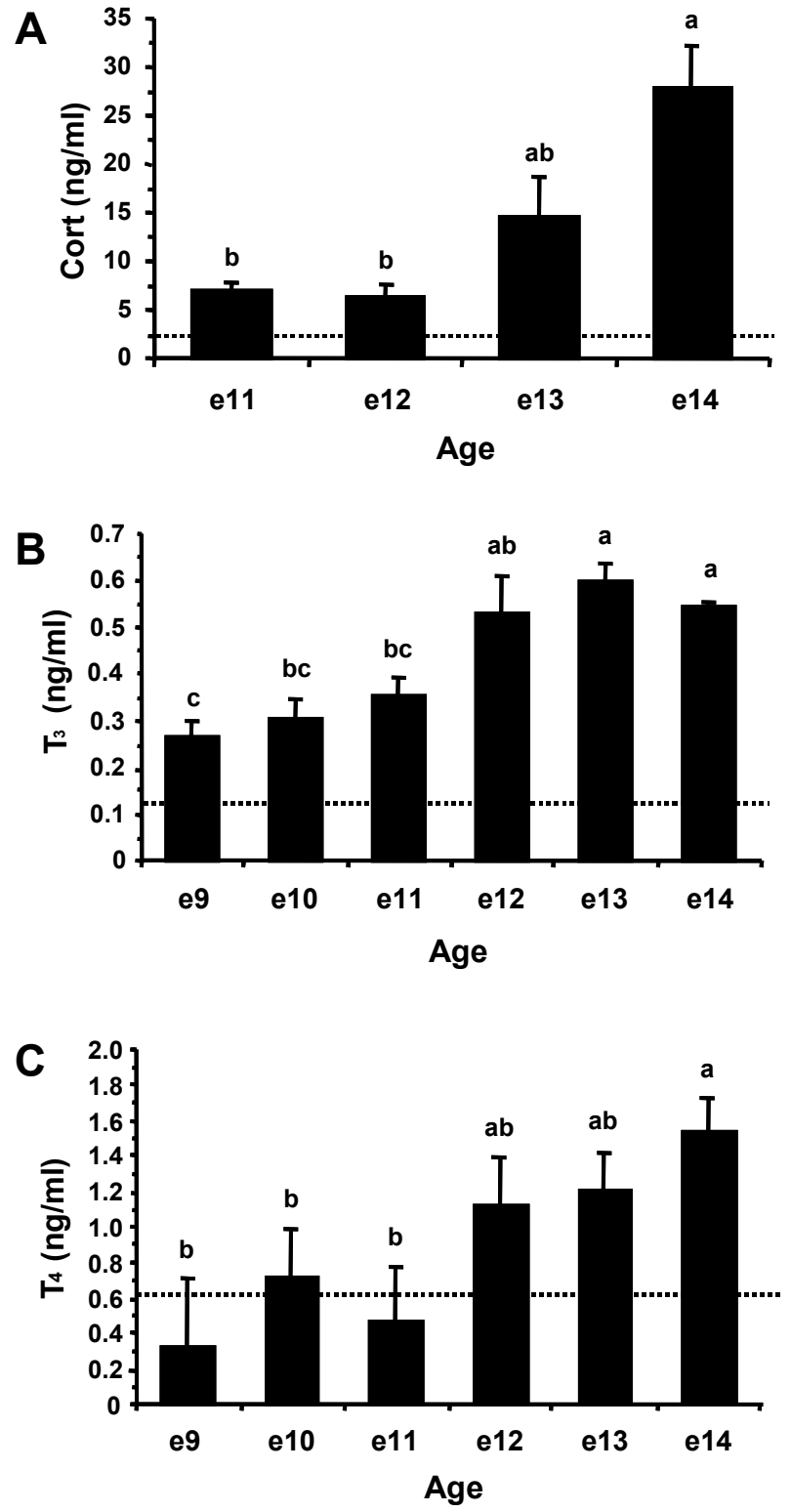

Figure 1 Plasma CORT and thyroid hormone levels in mid-embryogenesis determined by RIA. Plasma samples were collected on e9-e14, and CORT (A), total $\mathrm{T}_{3}$ (B) and total $\mathrm{T}_{4}$ levels (C) were measured by RIA. Results are the least squares means of three or four independent replicates. Data were analyzed by analysis of variance, followed by Tukey's Studentized range test. Values denoted by different letters are significantly different $(P<0 \cdot 05)$. Vertical bars represent the pooled S.E. of comparisons. Dashed lines denote the limit of detection in the RIAs. Note that levels of total $\mathrm{T}_{4}$ on e9, e10 and e11 were at or below the limit of detection.

thyroid hormones increase in the systemic circulation prior to the time of somatotroph differentiation, plasma samples were collected from chorioallantoic vessels of embryos, and total CORT levels (Fig. 1A), total $\mathrm{T}_{3}$ levels (Fig. 1B) and 
total $\mathrm{T}_{4}$ levels (Fig. 1C) were measured by RIA. Plasma total CORT could be detected at e11, e12 and e13 with levels of $6.9 \pm 0.9, \quad 6.3 \pm 1 \cdot 3$ and $14.5 \pm 4.2 \mathrm{ng} / \mathrm{ml}$ respectively (mean \pm pooled S.E.M.). However, total CORT levels increased by e14 to $27 \cdot 9 \pm 4 \cdot 2 \mathrm{ng} / \mathrm{ml}$. Data published on concentrations of adrenal hormones in plasma during development of the chick vary from several to several tens of $\mathrm{ng} / \mathrm{ml}$ (Wise \& Frye 1973, Kalliecharan \& Hall 1974, Marie 1981), comparable to our current data. Plasma $\mathrm{T}_{3}$ levels increased progressively from e9 to e14. The plasma total $T_{3}$ levels on e13 and e14 were significantly higher than those on e9, e10 and e11 $(P<0 \cdot 05)$. Plasma $T_{4}$ levels showed a similar pattern to $T_{3}$, although those on e9, e10 and e11 were at or below the level of sensitivity of the RIA. Furthermore, plasma total $\mathrm{T}_{4}$ levels on e14 were statistically higher than those on e9, e10 and e11 $(P<0 \cdot 05)$. Thus, plasma total CORT and total thyroid hormone levels increased just prior to normal somatotroph differentiation (e14) during chicken embryonic development.

Treatment with exogenous thyroid hormones increases somatotroph abundance in vivo

We found that both $\mathrm{T}_{4}$ and $\mathrm{T}_{3}$ could act with CORT to increase somatotroph abundance in vitro, although the effects of $\mathrm{T}_{3}$ were biphasic, inhibiting CORT actions at higher concentrations (Liu et al. 2003). The following experiments were designed to examine the effect of thyroid hormones on somatotroph abundance in vivo. On e11, the albumen of fertile eggs was injected with $T_{3}$ $(1.2 \mathrm{pg}, 12 \mathrm{pg}, 120 \mathrm{pg}, 1.2 \mathrm{ng}$ in $100 \mu \mathrm{l}$ water). The embryos were then allowed to continue developing until e13, when pituitary cells were isolated and subjected to RHPA to detect GH-secreting cells. Figure 2 presents the results from these trials. $T_{3}$ at $12 \mathrm{pg}$ and $120 \mathrm{pg}$ increased the proportions of $\mathrm{GH}$-secreting cells respectively to $7 \cdot 7 \pm 2 \cdot 1$ and $8 \cdot 3 \pm 2 \cdot 2 \%$ of all pituitary cells versus basal levels of $4 \cdot 0 \pm 2 \cdot 1 \%$ and water injection controls of $3 \cdot 8 \pm 2 \cdot 1 \% . \mathrm{T}_{3}$ at $1 \cdot 2 \mathrm{pg}$ and $1 \cdot 2 \mathrm{ng}$ slightly increased the percentage of GH-secreting cells, although these effects were not statistically significant. We also conducted a single experiment to test the effect of $\mathrm{T}_{3}$ on somatotroph abundance in vivo by ICC. Injection of $\mathrm{T}_{3}$ on e 11 at $12 \mathrm{pg}$, $120 \mathrm{pg}, 1.2 \mathrm{ng}$ and $12 \mathrm{ng}$ increased the percentage of GH-containing cells on e13 to $7 \cdot 4,9 \cdot 4,12.6$ and $8.0 \%$ respectively, versus the vehicle-injected control of $4 \cdot 6 \%$. Administration of $\mathrm{T}_{3}$ to developing embryos could, therefore, augment somatotroph proportions prematurely in vivo.

We also tested whether $\mathrm{T}_{4}$ administration could modulate somatotroph abundance in vivo. As we found previously that conversion of $\mathrm{T}_{4}$ to $\mathrm{T}_{3}$ was necessary for the effect of $\mathrm{T}_{4}$ on corticosterone induction of somatotrophs in culture (Liu et al. 2003), the albumen of fertile eggs was injected on e11 with $\mathrm{T}_{4}(1 \cdot 2 \mathrm{ng}, 12 \mathrm{ng}, 120 \mathrm{ng}$

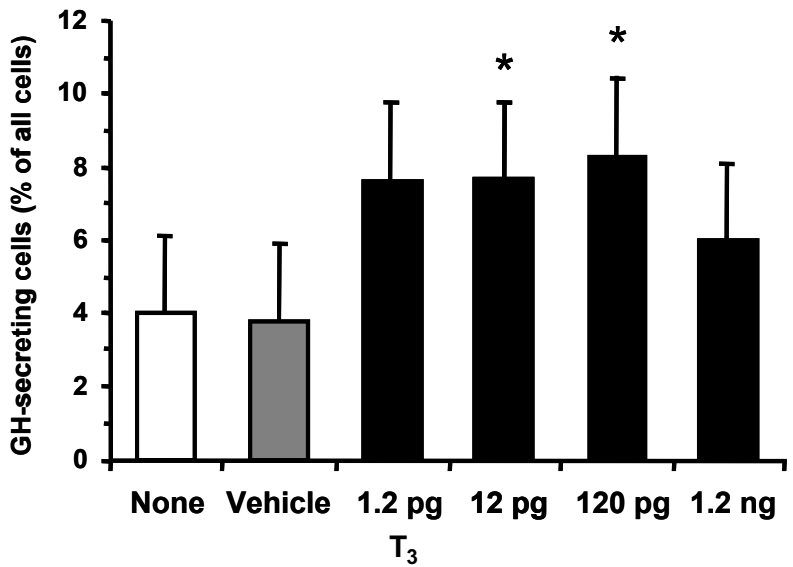

Figure 2 The effect of $\mathrm{T}_{3}$ on somatotroph abundance in vivo determined by RHPA. The albumen of fertile eggs was injected on e11 with $\mathrm{T}_{3}(1 \cdot 2 \mathrm{pg}, 12 \mathrm{pg}, 120 \mathrm{pg}$ and $1.2 \mathrm{ng}$ in $100 \mu \mathrm{l}$ water). The embryos were then allowed to continue developing until e13, when pituitary cells were isolated and subjected to RHPA for GH release. RHPAs were performed for $20 \mathrm{~h}$ in the presence of GHRH $\left(10^{-7} \mathrm{M}\right)$ to induce $\mathrm{GH}$ secretion. Three assay chambers were used for each group of treated cells. Results are reported as the percentage of $\mathrm{GH}$-secreting cells and are the least squares means of four independent replicate trials. Percentile results were transformed by taking the log of the arcsine of the ratio of $\mathrm{GH}$ cells to all pituitary cells. Transformed data were then analyzed by analysis of variance, followed by Tukey's Studentized range test. Values denoted by an asterisk $\left(^{*}\right)$ are significantly different from the vehicle-injected control $(P<0 \cdot 05)$. Vertical bars represent the pooled S.E. of comparisons.

and $1 \cdot 2 \mu \mathrm{g}$ in $100 \mu \mathrm{l}$ water) at $10^{3}$-fold greater doses than $\mathrm{T}_{3}$. Pituitary cells were isolated on e13 and subjected to ICC for GH-containing cells (Fig. 3). The percentage of GH-containing cells was increased by all doses of $\mathrm{T}_{4}$ $(P<0 \cdot 05)$, with the greatest effect on $\mathrm{GH}$ cell abundance $\left(11.9 \pm 0 \cdot 4 \%\right.$ of all cells) observed with $1 \cdot 2 \mu \mathrm{g} \mathrm{T}_{4}$, compared with $7 \cdot 9 \pm 0.5 \%$ for basal levels. Together with the results from $\mathrm{T}_{3}$ injections, these data indicate that treatment with exogenous thyroid hormones can increase somatotroph abundance during chick embryonic development in vivo.

\section{Inhibition of thyroid hormone synthesis suppresses normal somatotroph differentiation}

The goitrogen MMI is a common anti-thyroid drug that inhibits thyroid hormone biosynthesis. In the present study, we established hypothyroidism during midembryogenesis by administration of MMI. First, we conducted preliminary experiments on the dose and timing of MMI treatment needed to suppress somatotroph abundance. Injection of $5 \mu \mathrm{g}$ MMI on e9, e10, e11 or e12 decreased the percentage of $\mathrm{GH}$-containing cells on e14 to $1 \cdot 8,2 \cdot 2,2 \cdot 4$ and $3 \cdot 4 \%$ respectively, versus the vehicleinjected control of $5 \cdot 0 \%$; this suggests that $\mathrm{GH}$ cells were most sensitive to MMI treatment on e9. Injection of $5 \mu \mathrm{g}$ 


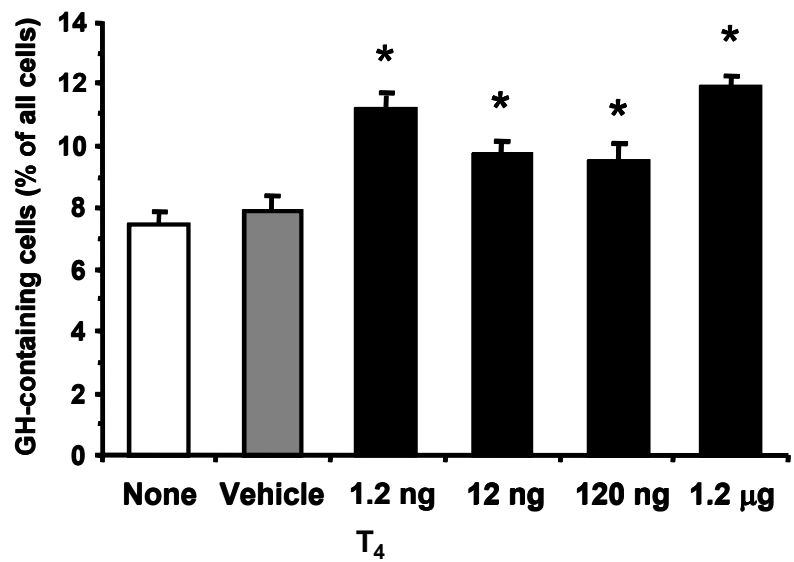

Figure 3 The effect of $\mathrm{T}_{4}$ on somatotroph abundance in vivo determined by ICC. The albumen of fertile eggs was injected on e11 with $\mathrm{T}_{4}(1 \cdot 2 \mathrm{ng}, 12 \mathrm{ng}, 120 \mathrm{ng}$ and $1 \cdot 2 \mu \mathrm{g}$ in $100 \mu \mathrm{l}$ water). The embryos were then allowed to continue developing until e13, when pituitary cells were isolated and subjected to ICC for GH. Results are reported as the percentage of GH-containing cells and are the least squares means of three independent replicate trials. Transformed data were analyzed as in Fig. 2, with values denoted by an asterisk $\left(^{*}\right)$ being significantly different from vehicle-injected controls $(P<0 \cdot 05)$. Vertical bars represent the pooled S.E. of comparisons.

MMI on e9 also reduced plasma $\mathrm{T}_{3}$ levels on e14 to $0.47 \pm 0.02 \mathrm{ng} / \mathrm{ml}$ (versus $0.59 \pm 0.02 \mathrm{ng} / \mathrm{ml}$ for the vehicle-injected group, $P<0 \cdot 05)$ and $\mathrm{T}_{4}$ levels on e14 to $0.78 \pm 0.13 \mathrm{ng} / \mathrm{ml}$ (versus $1.25 \pm 0.35 \mathrm{ng} / \mathrm{ml}$ for the vehicle-injected group). It has been reported that continuous infusion of MMI $(50 \mu \mathrm{g} / 0 \cdot 1 \mathrm{ml})$ from e15 to e19 blocked the hatchability of chicken embryos (Iqbal et al. 1987). We also determined whether injection of $5 \mu \mathrm{g}$ MMI on e9 was toxic to embryo growth by determining embryo body weights from e14 to 1 day after hatching. There were no significant differences in body weights between MMI-treated and control embryos (data not shown). We next evaluated the effect of MMI on somatotroph differentiation during embryonic development. We conducted four replicate trials in which $5 \mu \mathrm{g}$ MMI or vehicle were injected on e9 and somatotroph abundance was assessed on e14 by ICC (Fig. 4). MMI decreased the abundance of GH-containing cells on e14 from $13 \cdot 3 \pm 1 \cdot 3$ to $7 \cdot 6 \pm 1 \cdot 3 \%$ of all cells $(P<0 \cdot 05)$. These results suggest that the thyroid hormone synthesis inhibitor, MMI, suppressed somatotroph differentiation during embryonic development, although it did not affect embryo growth.

$T_{3}$ replacement reverses the reduction in somatotrophs induced by $M M I$

Based on the experiments described above, we determined (by ICC) that $1.2 \mathrm{ng}$ was the most effective dose of $\mathrm{T}_{3}$ administration to increase somatotroph abundance. We

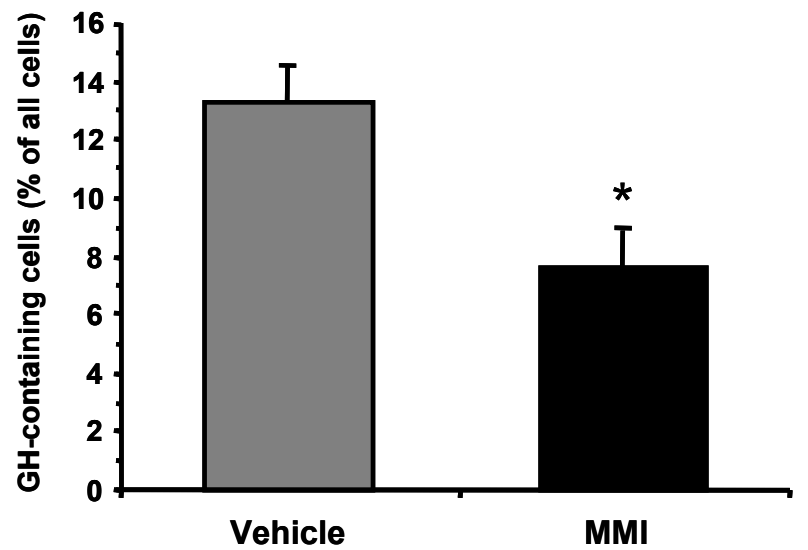

Figure 4 The effect of $\mathrm{MMI}$ on somatotroph differentiation in vivo as determined by ICC. The albumen of fertile eggs was injected on e9 with $5 \mu \mathrm{g} \mathrm{MMI}$ or vehicle $(100 \mu \mathrm{l})$. The embryos were then allowed to continue developing until e14, when pituitary cells were isolated and subjected to ICC for GH. Results are reported as the percentage of $\mathrm{GH}$-containing cells and are the least squares means of four independent replicate trials. Transformed data were analyzed as in Fig. 2, with the asterisk $\left(^{*}\right)$ indicating a significantly different value from the vehicle-injected controls $(P<0 \cdot 05)$. Vertical bars represent the pooled S.E. of comparisons.

next tested whether $\mathrm{T}_{3}$ could reverse the effect of MMI on somatotroph abundance. We injected $5 \mu \mathrm{g}$ MMI on e9 and $1.2 \mathrm{ng} \mathrm{T}_{3}$ on e11 into the same eggs, and determined somatotroph abundance on e14 by ICC. Figure 5 presents the results from these trials. Compared with basal levels of somatotrophs, MMI significantly decreased the proportion of GH-containing cells, while $\mathrm{T}_{3}$ alone augmented somatotroph abundance $(P<0 \cdot 05)$. Interestingly, $\mathrm{T}_{3}$

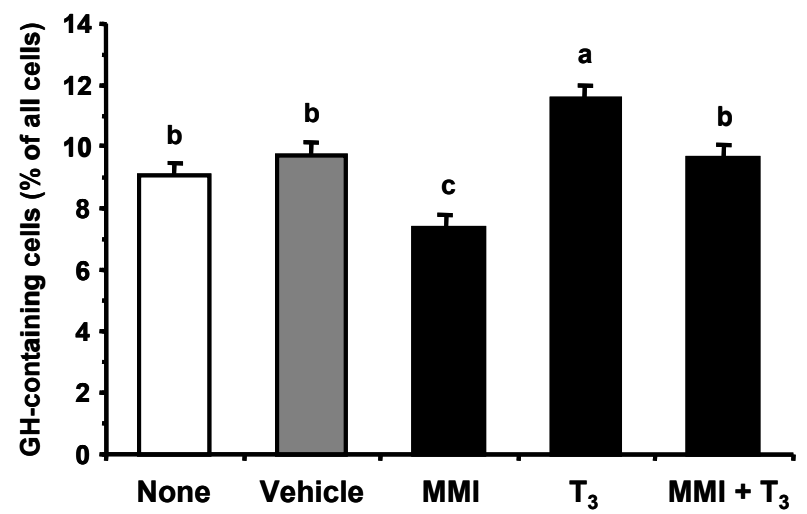

Figure 5 The effect of $T_{3}$ replacement on the reduction in somatotroph abundance induced by MMI. Fertile eggs were injected on e9 with $5 \mu \mathrm{g} \mathrm{MMI}$ and/or on e 11 with $1 \cdot 2 \mathrm{ng} \mathrm{T}_{3}$ in $100 \mu \mathrm{l}$ water. On e14, pituitary cells were isolated and subjected to ICC to identify GH-containing cells. Results are reported as the percentage of $\mathrm{GH}$-containing cells and are the least squares means of four independent replicate trials. Data were analyzed as in Fig. 2, with values denoted by different letters being significantly different from water-injected controls $(P<0 \cdot 05)$. Vertical bars represent the pooled S.E. of comparisons. 
treatment overcame the reduction in GH cell abundance induced by the thyroid hormone synthesis inhibitor, MMI $(P<0 \cdot 05$, relative to MMI alone). Thus, endogenous thyroid hormone synthesis may contribute to normal somatotroph differentiation.

\section{Discussion}

During chicken embryonic development, which lasts 21 days, somatotrophs are rare before e12, and significant somatotroph differentiation occurs between e14 and e16 (Porter et al. 1995a). We and others have shown that GH-secreting cells do not differentiate spontaneously without an extrapituitary signal, and glucocorticoids were found to increase the abundance of GH mRNA and induce somatotroph differentiation in chicken embryos and fetal rats both in vitro and in vivo (Hemming et al. 1988, Nogami \& Tachibana 1993, Morpurgo et al. 1997, Nogami et al. 1997, Dean et al. 1999, Bossis \& Porter 2000, 2003, Porter et al. 2001). Low levels of CORT can be detected in the circulation by day 10 of chicken embryonic development (Wise \& Frye 1973, Kalliecharan \& Hall 1974), and our current study and other reports showed a substantial increase in plasma CORT levels around e13-e14 (Woods et al. 1971, Marie 1981, Tanabe et al. 1986), just prior to somatotroph differentiation at e14-e16 (Porter et al. 1995a). It is also noted that the levels of transcortin, the circulating glucocorticoid-binding protein, increase significantly around e15 (Gasc \& Martin 1978). Taken together, these findings suggest a close correlation between increased adrenal CORT production and somatotroph differentiation.

In the developing chicken embryo, the ontogeny and maturation of the hypothalamo-adenohypophysealthyroid (HAT) axis has been studied extensively. Thyrotropin-releasing hormone (TRH) is immunocytochemically demonstrable in the infundibulum as early as e4.5, with a gradual increase in the number of TRHpositive perikarya, as well as the amount of immunoreactive TRH per cell, from e 4.5 to e $19 \cdot 5$ (Thommes et al. 1985). Similarly, immunoreactive thyroid-stimulating hormone (TSH) is found in the pituitary by e6.5 (Thommes et al. 1992), and thyrotrophs are responsive to TRH at this same age, as evidenced by heightened plasma $\mathrm{T}_{4}$ levels following TRH treatment (Thommes \& Hylka 1978). However, it is between e 10.5 and e 11.5 that there is a marked increase in both the number of TSHimmunoreactive cells and the amount of immunoreactive material per cell (Thommes et al. 1983). Immunoreactive $\mathrm{T}_{3}$ was first detected at e9 in the colloid of primordial thyroid follicles and gradually increased with embryo age (Kameda et al. 1986). Our data indicate that plasma thyroid hormones steadily increase from e9 to e14, with significantly higher concentrations at e13 $\left(\mathrm{T}_{3}\right)$ or e14 $\left(\mathrm{T}_{4}\right)$ than e9-e11. Although the yolk of the hen's egg contains both $\mathrm{T}_{4}$ and $\mathrm{T}_{3}$ as the maternal contribution of thyroid hormones to the developing embryo (Prati et al. 1992), the thyroidal origin of plasma thyroid hormone has been established by the finding that both thyroidectomy and thiourea treatment markedly reduce circulating $T_{4}$ levels at day 10.5 of incubation (Thommes \& Tonetta 1979, Thommes et al. 1984). Furthermore, hypophysectomy and hormone replacement studies show that functionality of the HAT axis occurs between e10.5 and e 12.5 of development (Thommes et al. 1977, Thommes 1987). Thus, circulating thyroid hormones in the embryo are principally derived from the embryonic thyroid gland, under the control of the hypothalamo-pituitary axis, by the time of somatotroph differentiation. In contrast to large mammals, birds possess only two types of thyroid hormone-binding plasma proteins, i.e. albumin and transthyretin, and not thyroxine-binding globulin. There are no reports describing the ontogeny of thyroid hormone-binding proteins during chicken embryonic development. However, similar patterns of circulating $\mathrm{T}_{3}$ and $\mathrm{T}_{4}$ concentrations have been observed in quail embryos (McNabb \& Hughes 1983). Total serum protein and $T_{4}$ binding increased significantly from e11 to e16, while $T_{3}$ binding was essentially equal to adult levels. Most $\mathrm{T}_{3}$ and $\mathrm{T}_{4}$ in the circulation was bound to plasma proteins. Thus, free $T_{3}$ and free $T_{4}$ available to somatotrophs may be reduced. However, the affinity of albumin and transthyretin for thyroid hormones is relatively low.

Multiple studies suggest that thyroid hormones can activate $\mathrm{GH}$ synthesis in adult rats and synergistically stimulate somatotroph abundance with glucocorticoids in rat pituitary cell lines (Hervas et al. 1975, Shapiro et al. 1978, Dobner et al. 1981, Spindler et al. 1982, Yaffe \& Samuels 1984). In contrast, thyroid hormones appear to require glucocorticoids in order to regulate $\mathrm{GH}$ gene expression and somatotroph differentiation in fetal animals. Dexamethasone treatment of pregnant rats via their drinking water induced $\mathrm{GH}$ and $\mathrm{GH}$ mRNA accumulation in the fetal pituitary gland on day 17 or 18 of gestation, when substantial GH expression had not yet occurred in the control fetuses. Additional $\mathrm{T}_{4}$ injections into the peritoneum of the pregnant females enhanced the effect of dexamethasone, whereas $\mathrm{T}_{4}$ exhibited no effect when given alone (Nogami et al. 1995). Furthermore, GH immunoreactivity could be induced in the fetal rat pituitary primordia in vitro with cortisol. $\mathrm{T}_{3}$, which was individually ineffective, acted synergistically with cortisol to increase GH cell density (Hemming et al. 1988). As in mammals, thyroid hormones are thought to be involved in the control of growth and development of a number of organs, including the brain, liver and skeleton in early and mid-embryonic development of birds (Scanes et al. 1987). However, there have been no reported studies on the effects of thyroid hormones on growth hormone synthesis and somatotroph differentiation during chicken embryonic development. We reported previously that $\mathrm{T}_{3}$ or $\mathrm{T}_{4}$ alone 
had minimal effects on the percentage of somatotrophs in e11 pituitary cell cultures, while both $\mathrm{T}_{4}$ and $\mathrm{T}_{3}$ could act in combination with CORT to increase somatotroph abundance. In that study, the effects of $\mathrm{T}_{3}$ were biphasic, inhibiting CORT actions at higher concentrations (Liu et al. 2003). In the present study, we demonstrated that treatment with exogenous thyroid hormones on e11 increased somatotroph abundance on e13. The ineffectiveness of the highest dose of $T_{3}$ tested in the present study may reflect the biphasic actions of $\mathrm{T}_{3}$ noted in cell culture previously (Liu et al. 2003). The comparable effectiveness of all doses of $\mathrm{T}_{4}$ tested in our current investigation may reflect a limited capacity for conversion of $T_{4}$ to $T_{3}$ within the embryonic pituitary gland, as indicated in our previous report (Liu et al. 2003). In our previous study, we found that the deiodinase inhibitor iopanoic acid blocked the effect of $\mathrm{T}_{4}$ but not $\mathrm{T}_{3}$ in vitro. Thus, we believe that conversion of $T_{4}$ to $T_{3}$ is necessary for the somatotroph response. As plasma CORT levels increased around e13-e14, and thyroid hormones alone are individually ineffective in culture, we conclude that the induction of somatotrophs by exogenous thyroid hormones requires interaction with endogenous glucocorticoids in vivo. In contrast, $\mathrm{T}_{4}$ injection failed to induce either $\mathrm{GH}$ cells or the accumulation of $\mathrm{GH}$ in fetal rat pituitary glands on e17 of gestation (Nogami et al. 1995). However, that study did not assess the effect of $\mathrm{T}_{4}$ on day 18 or 19 of gestation, the time that somatotroph differentiation begins. Species differences could also explain the discrepancy between the current study in chickens and the rats used in Nogami et al. (1995).

Plasma concentrations of thyroid hormones were profoundly depressed, both in chick embryos and growing chickens, after surgical thyroidectomy or MMI treatment (Harvey et al. 1983, Leung et al. 1985, Iqbal et al. 1987). Consequently, reduction of physiological levels of thyroid hormones impairs the growth and development of the chick embryo. This is evident with MMI treatment, which significantly reduces body weight gain and bone growth during the second half of embryogenesis, and delays the onset of pipping and hatching (King \& May 1984, Iqbal et al. 1987). This effect of MMI on growth can be reversed by $\mathrm{T}_{4}$ treatment in ovo (King \& May 1984). In the present study, we also used MMI to suppress thyroid hormone synthesis. To eliminate confounding effects, a dose of MMI was chosen that did not affect body weight. As a result, suppression of thyroid hormone levels in our study was not as great as that reported previously (King \& May 1984, Iqbal et al. 1987). However, we did find that injection of MMI significantly suppressed normal somatotroph differentiation, while $\mathrm{T}_{3}$ treatment overcame the reduction in GH cell abundance induced by MMI. These results strongly suggest that thyroid hormone synthesis plays a significant role in the regulation of normal somatotroph differentiation in vivo. Similarly, treatment of pregnant female rats with MMI resulted in marked reductions in the number of GH cells, pituitary content of $\mathrm{GH}$, and GH mRNA levels in the gestating rat fetuses, and this suppression was partially reversed by $\mathrm{T}_{4}$ replacement (Morreale de Escobar et al. 1993, Nogami et al. 1995). However, no evidence indicated whether the circulating thyroid hormones in the rat fetuses originated from the fetuses or their mother. Thus, the possibility that thyroid hormones modulated somatotroph differentiation indirectly in the fetuses through maternal effects could not be eliminated in the earlier rat studies. In our current study, we demonstrate direct effects of thyroid hormones on somatotroph differentiation in chicken embryos in the absence of maternal-fetal interactions.

Our results indicate that normal somatotroph ontogeny involves peripheral thyroid hormone production. We have shown previously (Liu et al. 2003) that thyroid hormones and glucocorticoids can interact in cell cultures to induce GH cell differentiation, suggesting a direct mode of action within the pituitary. We have also shown that the effects of glucocorticoids on induction of GH mRNA are indirect within the pituitary and require synthesis of some other protein(s) (Bossis and Porter 2003). One possible explanation for the observed effects of thyroid hormones is that thyroid hormone receptors and glucocorticoid receptors interact directly to regulate production of the unknown intermediate protein, which in turn induces $\mathrm{GH}$ gene expression. A second possibility is that thyroid hormone receptors interact with the glucocorticoid-induced protein(s) to augment GH gene expression. Evaluation of these possibilities awaits identification of the glucocorticoid-induced intermediate protein(s).

In conclusion, the present findings indicate that treatment with exogenous thyroid hormones can modulate somatotroph abundance and that endogenous thyroid hormone synthesis contributes to normal somatotroph differentiation during chicken embryonic development. Since we reported that $\mathrm{T}_{3}$ alone was ineffective in vitro, we interpret these findings to indicate that the effects of thyroid hormone treatments in vivo were due to interactions with endogenous glucocorticoids.

\section{Funding}

This research was supported by competitive grant 00-35206-9463 (to T E Porter) from the USDA-NRI program.

\section{References}

Bossis I \& Porter TE 2000 Ontogeny of corticosterone-inducible growth hormone-secreting cells during chick embryonic development. Endocrinology 141 2683-2690.

Bossis I \& Porter TE 2003 Evaluation of glucocorticoid-induced growth hormone gene expression in chicken embryonic pituitary cells using a novel in situ mRNA quantitation method. Molecular and Cellular Endocrinology 201 13-23. 
Dean CE, Morpurgo B \& Porter TE 1999 Induction of somatotroph differentiation in vivo by corticosterone administration during chick embryonic development. Endocrine 11 151-156.

Dobner PR, Kawasaki ES, Yu LY \& Bancroft FC 1981 Thyroid or glucocorticoid hormone induces pre-growth-hormone mRNA and its probable nuclear precursor in rat pituitary cells. PNAS $\mathbf{7 8}$ 2230-2234.

Dubois PM \& Hemming FJ 1991 Fetal development and regulation of pituitary cell types. Journal Electron Microscopy Techniques 19 2-20.

Dubois PM, el Amraoui A \& Heritier AG 1997 Development and differentiation of pituitary cells. Microscopy Research and Techniques 39 98-113.

Gasc JM \& Martin B 1978 Plasma corticosterone binding capacity in the partially decapitated chick embryo. General and Comparative Endocrinology 35 274-279.

Harvey S, Sterling RJ \& Klandorf H 1983 Concentrations of triiodothyronine, growth hormone, and luteinizing hormone in the plasma of thyroidectomised fowl (Gallus domesticus). General and Comparative Endocrinology 50 275-281.

Hemming FJ, Aubert ML \& Dubois PM 1988 Differentiation of fetal rat somatotropes in vitro: Effects of cortisol, 3,5,3'-triiodothyronine, and glucagon, a light microscopic and radioimmunological study. Endocrinology 123 1230-1236.

Hervas F, Morreale de Escobar G \& Escobar Del Rey F 1975 Rapid effects of single small doses of L-thyroxine and triiodo-L-thyronine on growth hormone, as studied in the rat by radioimmunoassay. Endocrinology 97 91-101.

Iqbal A, Decuypere E, Kuhn ER, Schneider R, Verheyen G \& Huybrechts LM 1987 The influence of methimazole on the thyrotrophic and peripheral activity of thyrotrophin and thyrotrophin-releasing hormone in the chick embryo and growing chicken. Domestic Animal Endocrinology 4 291-298.

Kalliecharan R \& Hall BK 1974 A developmental study of the levels of progesterone, corticosterone, cortisol, and cortisone circulating in plasma of chick embryos. General and Comparative Endocrinology 24 364-372.

Kameda Y, Udatsu K, Horino M \& Tagawa T 1986 Localization and development of immunoreactive triiodothyronine in thyroid glands of dogs and chickens. Anatomy Research 214 168-176.

King DB \& May JD 1984 Thyroidal influence on body growth. Journal of Experimental Zoology 232 453-460.

Leung FC, Taylor JE \& Van Iderstine A 1985 Effects of dietary thyroid hormones on growth, plasma T3 and T4, and growth hormone in normal and hypothyroid chickens. General and Comparative Endocrinology 59 91-95.

Liu L, Dean CE \& Porter TE 2003 Thyroid hormones interact with glucocorticoids to affect somatotroph abundance in chicken embryonic pituitary cells in vitro. Endocrinology 144 3836-3841.

McNabb FM \& Hughes TE 1983 The role of serum binding proteins in determining free thyroid hormone concentrations during development in quail. Endocrinology 113 957-963.

Marie C 1981 Ontogenesis of the adrenal glucocorticoids and of the target function of the enzymatic tyrosine transaminase activity in the chick embryo. Journal of Endocrinology 90 193-200.

Morpurgo B, Dean CE \& Porter TE 1997 Identification of the blood-borne somatotroph-differentiating factor during chicken embryonic development. Endocrinology 138 4530-4535.

Morreale de Escobar G, Calvo R, Escobar del Rey F \& Obregon MJ 1993 Differential effects of thyroid hormones on growth and thyrotropic hormones in rat fetuses near term. Endocrinology 132 2056-2064.

Nogami H \& Tachibana T 1993 Dexamethasone induces advanced growth hormone expression in the fetal rat pituitary gland in vivo. Endocrinology 132 517-523.

Nogami H, Yokose T \& Tachibana T 1995 Regulation of growth hormone expression in fetal rat pituitary gland by thyroid or glucocorticoid hormone. American Journal of Physiology 268 E262-E267.
Nogami H, Inoue K \& Kawamura K 1997 Involvement of glucocorticoid-induced factor(s) in the stimulation of growth hormone expression in the fetal rat pituitary gland in vitro. Endocrinology 138 1810-1815.

Porter TE, Couger GS, Dean CE \& Hargis BM 1995a Ontogeny of growth hormone $(\mathrm{GH})$-secreting cells during chicken embryonic development: initial somatotrophs are responsive to GH-releasing hormone. Endocrinology 136 1850-1856.

Porter TE, Couger GS \& Morpurgo B $1995 b$ Evidence that somatotroph differentiation during chicken embryonic development is stimulated by a blood borne signal. Endocrinology 136 3721-3728.

Porter TE, Dean CE, Piper MM, Medvedev KL, Ghavam S \& Sandor J 2001 Somatotroph recruitment by glucocorticoids involves induction of growth hormone gene expression and secretagogue responsiveness. Journal of Endocrinology 169 499-509.

Prati M, Calvo R, Morreale G \& Morreale de Escobar G 1992 L-Thyroxine and 3,5,3'-triiodothyronine concentrations in the chicken egg and in the embryo before and after the onset of thyroid function. Endocrinology 130 2651-2659.

Scanes CG, Hart LE, Decuypere E \& Kuhn ER 1987 Endocrinology of the avian embryo: an overview. Journal of Experimental Zoology, Supplement 1 253-264.

Shapiro LE, Samuels HH \& Yaffe BM 1978 Thyroid and glucocorticoid hormones synergistically control growth hormone mRNA in cultured GH1 cells. PNAS 75 45-49.

Spindler SR, Mellon SH \& Baxter JD 1982 Growth hormone gene transcription is regulated by thyroid and glucocorticoid hormones in cultured rat pituitary tumor cells. Journal of Biological Chemistry 257 11627-11632.

Tanabe Y, Saito N \& Nakamura T 1986 Ontogenetic steroidogenesis by testes, ovary, and adrenals of embryonic and postembryonic chickens (Gallus domesticus). General and Comparative Endocrinology 63 456-463.

Thommes RC 1987 Ontogenesis of thyroid function and regulation in the developing chick embryo. Journal of Experimental Zoology, Supplement 1 273-279.

Thommes RC \& Hylka VW 1978 Hypothalamo-adenohypophysealthyroid interrelationships in the chick embryo. I. TRH and TSH sensitivity. General and Comparative Endocrinology 34 193-200.

Thommes RC \& Tonetta SA 1979 Hypothalamo-adenohypophysealthyroid interrelationships in the chick embryo. II. Effects of thiourea treatment on plasma total thyroxine levels and thyroidal ${ }^{125}$ I uptake. General and Comparative Endocrinology 37 167-176.

Thommes RC, Vieth RL \& Levasseur S 1977 The effects of hypophysectomy by means of surgical decapitation on thyroid function in the developing embryo. General and Comparative Endocrinology 31 29-36.

Thommes RC, Martens JB, Hopkins WE, Caliendo J, Sorrentino MJ \& Woods JE 1983 Hypothalamo-adenohypophyseal-thyroid interrelationships in the chick embryo. IV. Immunocytochemical demonstration of TSH in the hypophyseal pars distalis. General and Comparative Endocrinology 51 434-443.

Thommes RC, Clark NB, Mok LL \& Malone S 1984 Hypothalamo-adenohypophyseal-thyroid interrelationships in the chick embryo. V. The effects of thyroidectomy on T4 levels in blood plasma. General and Comparative Endocrinology 54 324-327.

Thommes RC, Caliendo J \& Woods JE 1985 Hypothalamoadenohypophyseal-thyroid interrelationships in the developing chick embryo. VII. Immunocytochemical demonstration of thyrotrophin-releasing hormone. General and Comparative Endocrinology 57 1-9.

Thommes RC, Fitzsimons EJ, Davis M \& Woods JE 1992 Immunocytochemical demonstration of $\mathrm{T}_{4}$ content and TSH-binding by cells of the thyroid of the developing chick embryo. General and Comparative Endocrinology 85 79-85.

Wise PM \& Frye BE 1973 Functional development of the hypothalamo-hypophyseal-adrenal cortex axis in the chick embryo, Gallus domesticus. Journal of Experimental Zoology 185 277-292. 
Woods JE, De Vries GW \& Thommes RC 1971 Ontogenesis of the pituitary-adrenal axis in the chick embryo. General and Comparative Endocrinology 17 407-415.

Yaffe BM \& Samuels HH 1984 Hormonal regulation of the growth hormone gene. Relationship of the rate of transcription to the level of nuclear thyroid hormone-receptor complexes. Journal of Biological Chemistry 259 6284-6291.
Received 27 June 2003

Accepted 26 September 2003

Made available online as an

Accepted Preprint 1 October 2003 